\title{
Changing Trends in Antibiotic Resistance of Organism from Urinary Tract Infections Over Five Years in VIMS Ballari, Karnataka, India
}

\author{
Mariraj Jeer and Khutija Sarah* \\ Department of Microbiology, VIMS Ballari, India \\ *Corresponding author
}

\section{A B S T R A C T}

\begin{tabular}{l} 
Key w or d s \\
Urinary tract \\
infection, \\
Antibiotic \\
$\begin{array}{l}\text { Resistance, } \\
\text { Ciprofloxacin. }\end{array}$ \\
Article Info \\
$\begin{array}{l}\text { Accepted: } \\
29 \text { May } 2017 \\
\text { Available Online: } \\
\text { 10 June } 2017\end{array}$ \\
\hline
\end{tabular}

The aim of the present study was to examine the changes in the trend of antibiotic resistance of organisms from urinary tract infection over a five-year period in our hospital. The data selected were all urine cultures from the hospital urine samples over a five-year period. Results of urine cultures from patients throughout the hospital were analysed and information on susceptibility to four antibiotics i.e., Gentamycin, Amikacin, Ciprofloxacin and Nitrofurantoin was collected. Total number of urine samples in the study period were 15949 , out of which 5690(35.67\%) showed the growth of bacteria with significant count. E. coli was the commonest organism isolated followed by Klebsiella spp., Pseudomonas, $S$. aureus and others. Ciprofloxacin resistance has been increasing since past five years (2012 -33\% and 2016-40\%), and even gentamycin resistance has increased since past five years in (2012-31\% and 2016-33\%) also statistically amikacin show rise in resistance pattern(2012-31\% compared to 2016-36\%)As resistance to nitrofurantoin is less compared to other drugs i.e., (2012-14\% and in 2016-17\%). Nitrofurantoin resistance is low compared to other drugs. It is both cost effective and efficacious for empirical treatment of uncomplicated UTIs therefore should be considered the mainstay of treatment of uncomplicated UTIs. This can be switched to targeted therapy on the basis of definitive subsequent culture and AST results.

\section{Introduction}

Urinary tract infection [UTI] is one of the most common infections diagnosed in outpatient and in hospitalized patients (Vasudevan, 2014) worldwide about 150 million people are being diagnosed with urinary tract infection every year (Manikandan et al., 2011).

It is caused by gram positive and gram negative organisms (Alsamarai et al., 2016). Inappropriate use of antibiotics has led to increasing resistance rates in Gram negative bacteria against standard antibiotics with the increase rate of extended spectrum beta-lactamase in urinary organism, the treatment of UTIs has become more complex and more difficult (Alicem et al., 2012). The purpose of this study is to optimise outcomes which minimises excess broad-spectrum antimicrobial use, which can drive resistance selection pressures and be associated with secondary problems such as Clostridium difficile infection. It is important to continually monitor changes in antibiotic 
susceptibility in order to ensure that treatment remain appropriate (Penelope et al.,).

\section{Materials and Methods}

The data selected were all urine cultures from the hospital urine samples over a five-year period i.e., 2012 to 2016.

Results of urine cultures from patients throughout the hospital were analysed and Information on susceptibility to four antibiotics i.e., Gentamycin, Amikacin, Ciprofloxacin, Nitrofurantoin were collected.

\section{Results and Discussion}

Total number of urine samples in the study period were 15949, out of which 5690 (35.67\%) showed the growth of bacteria with significant count. E. coli was the commonest organism isolated followed by Klebsiella spp. Pseudomonas, S. aureus and others (Figs. 1 and 2). Ciprofloxacin resistance has been increasing since past five years (2012 -33\% and 2016-40\%) and even gentamycin resistance has increased since past five years in $(2012-31 \%$ and 2016-33\%) also statistically amikacin show rise in resistance pattern (2012-31\% compared to 2016-36\%), As resistance to Nitrofurantoin is less compared to other drugs i.e., (2012-14\% and in $2016-17 \%$ ).

UTIs are the most common bacterial infections among the community and hospital-acquired infections. In recent years, resistance rates to commonly used antibiotics increase rapidly and the treatment of UTIs has become more difficult (Alicem et al.,), ciprofloxacin resistance has been increasing since past five years (2012: $33 \%$ and 2016: $40 \%$ ), and even gentamycin resistance has increased since past five years in (2012: $31 \%$ and 2016: 33\%) also statistically amikacin show rise in resistance pattern (2012: $31 \%$ compared to 2016: $36 \%$ ). and resistance to Nitrofurantoin is less compared to other drugs (i.e., 2012-14\% and in 2016-17\%) (Fig. 3). Nitrofurantoin is a broad-spectrum bactericidal antibiotic, and it is use for more than four decades no clinically significant resistance has developed, as seen with other commonly used antibiotics. This is probably because Nitrofurantoin has multiple sites and levels of action in contrast to antibiotics that attack a single target like ampicillin or two targets like cotrimoxazole.

Fig.1 Positive and negative culture of urine samples

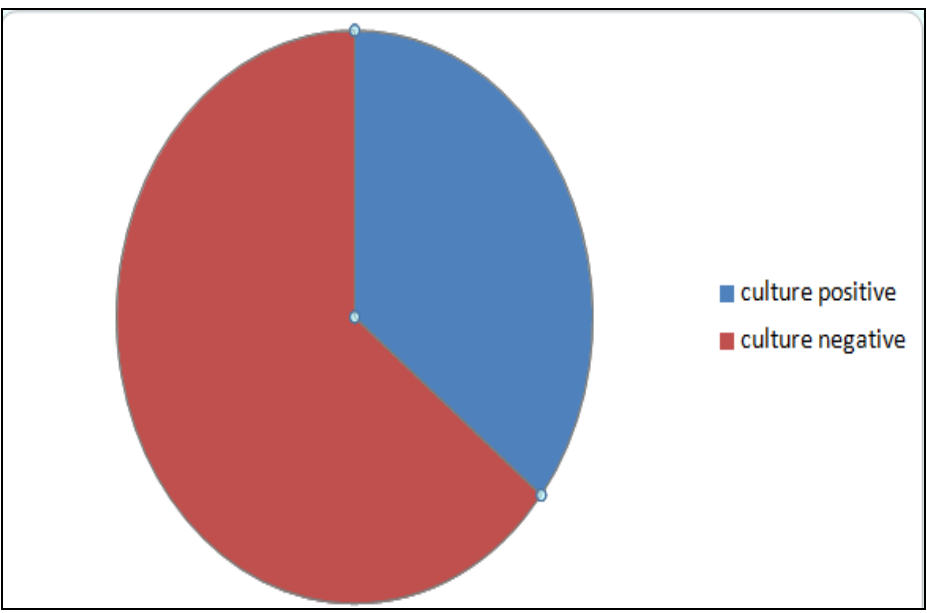


Fig.2 Common organism isolated in study

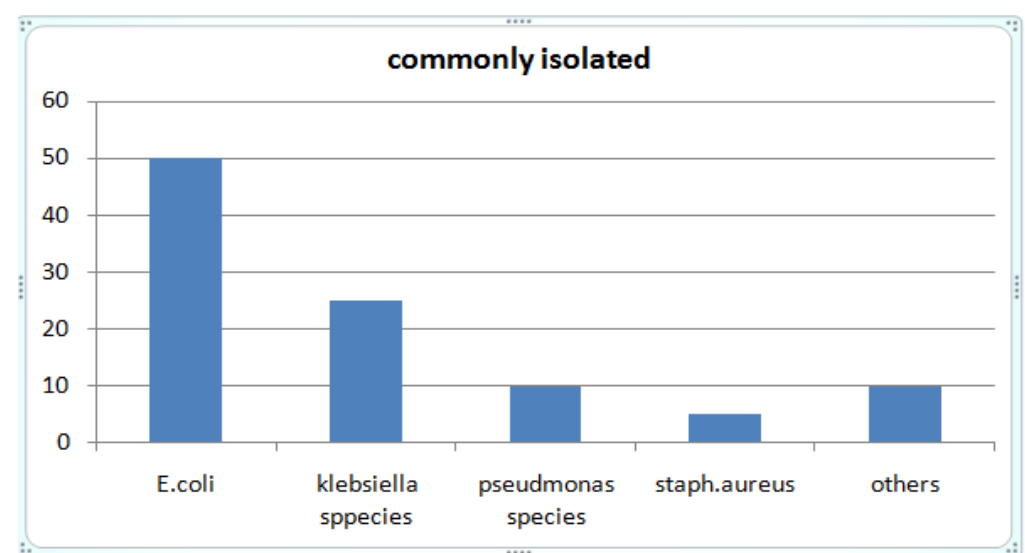

Fig.3 Sensitivity of the drugs in the following years

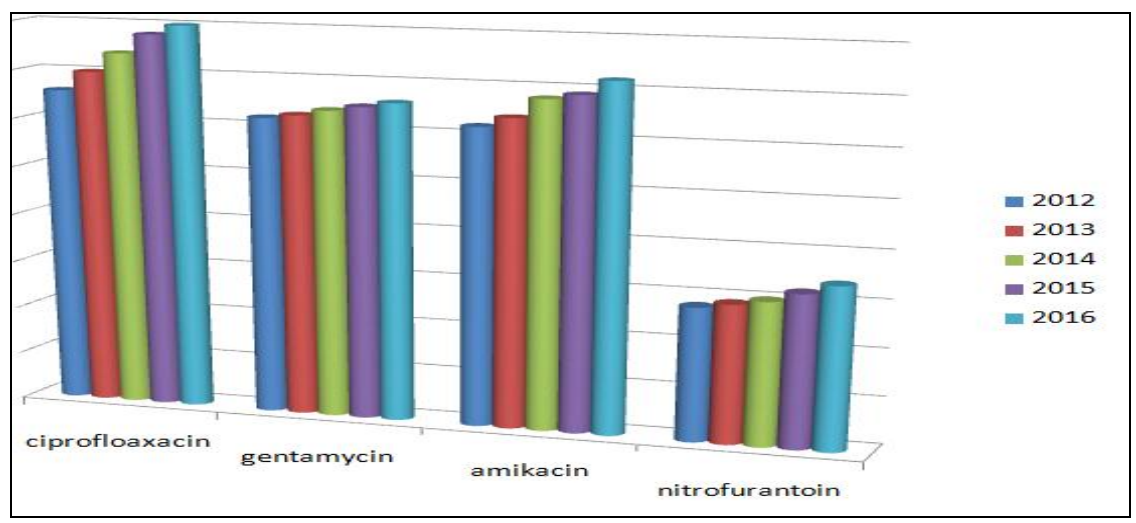

Bacterial nitroreductase enzyme converts nitrofurantoin to highly reactive electrophilic intermediates which non-specifically attack bacterial ribosomal proteins resulting in complete inhibition of protein synthesis (McOsker et al., 1994), and cause singlestrand breaks in DNA (McCalla et al., 1970). Nitrofurantoin is usually well tolerated. Side-effects occur at rates $<0.001 \%$ Nitrofurantoin is active against most common uropathogens including E. coli, Citrobacter spp, Staphylococcus saprophyticus and Enterococcus spp. Whereas, Enterobacter spp. and Klebsiella spp. are only moderately inhibited, Proteus spp, Providencia spp, Morganella morgannii, Serratia sp, Pseudomonas spp., and Acinetobacter spp. are mostly resistant to nitrofurantoin (Ronald et al., 1967; Barry, 1990).
In conclusion nitrofurantoin resistance is low compared to other drugs. It is both cost effective and efficacious for empirical treatment of uncomplicated UTIs therefore should be considered the mainstay of treatment of uncomplicated UTIs, since most of the organism like E. coli, Staphylococcus are regularly isolated from urine samples. Nitrofurantoin can be an alternative antibiotic but to be used judiciously.

\section{References}

Alicem Tekin, et al. 2012. In vitro efficasy of nitrofurantoin and some antibiotics in $E$. coli strain isolated from urine culture, New J. Med., 29(2): 89-91.

Alicem Tekin, Tuba Dal, Özcan Deveci, Recep Tekin, Hasan Bozdağ, Tuncer 
Özekinci. In Vitro Efficacy of Nitrofurantoin and Some Antibiotics in Escherichia coli Strains Isolated from Urine Cultures. Dicle University Faculty of Medicine Department of Medical Microbiology, DIYYARBAKIRDicle University Faculty of Medicine Department of Infectious Diseases, Diyarbakir.

Alsamarai, A.G.M., Ali, S. 2016. Urinary tract infection in female in Kirkuk city, Iraq: causative Nagents and antibiogram. World J. Pharm. Pharmaceut. Sci., 5(6): 261-273

Alsamarai, A.G.M., Ali, S. 2016. Urinary tract infection in female in Kirkuk city, Iraq: risk factors. World J. Pharm. Pharmaceut. Sci., 5(6): 180-195.

Barry, A.L. 1990. Nitrofurantoin susceptibility test criteria. $J$. Antimicrobial Chemother., 25: 711-3.

Manikandan, S., et al. 2011. Antimicrobial susceptibility pattern of urinary tract infection causing human pathogenic bacteria. Asian J. Med. Sci., 3(2): 56-60.
McCalla, D.R., et al. 1970. Mode of action of nitrofurazone. J. Bacteriol., 104: 112634.

McOsker, C.C., et al. 1994. Nitrofurantoin: mechanism of action and implications for resistance development in common uropathogens. J. Antimicrobial Chemother., 33(Suppl A): 23-30.

Penelope Teoh, Adriana Basarab, Ruth Pickering, Ahmed Ali, Matthew Hayes and Bhaskar K. Somani. Changing trends in antibiotic resistance for urinary $E$. coli infections over five years in a university hospital.

Ronald, A.R., Turck, M. 1967. Comparison of oxafuradene and nitrofurantoin in vitro and clinical assessment of oxafuradene in bacteriuria. Antimicrob. Agents Chemother., (Bethesda) 7: 506-9.

Vasudevan, R. 2014. Urinary tract infection: an overview of the infection and the associated risk factors. J. Microbiol. Exp., $\quad$ 1: $\quad 00008$. DOI:10.15406/jmen.2014.01.00008.

\section{How to cite this article:}

Mariraj Jeer and Khutija Sarah. 2017. Changing Trends in Antibiotic Resistance of Organism from Urinary Tract Infections Over Five Years in Vims Ballari. Int.J.Curr.Microbiol.App.Sci. 6(6): 2522-2525. doi: https://doi.org/10.20546/ijcmas.2017.606.300 